\title{
Henri Lefebvre's Criticism of Symbol Consumption Alienation in the Context of Everyday Life
}

\author{
Xiaying Lv \\ School of Marxism, Zhejiang University \\ Hangzhou, Zhejiang Province, China \\ e-mail: 775987695@qq.com
}

\begin{abstract}
Lefebvre believes that the phenomenons of alienation are not disappeared in modern times, but develops more new patterns. Capitalism is a comprehensive alienation of life, which is most vividly reflected in the consumption field. At the same time, consumption alienation has transcended labor alienation and become the main performance of alienation in the modern world. The critique of consumption alienation based on the context of everyday life opens up a critical perspective of the symbolic consumption alienation, thus creating a new perspective for the criticism of consumption alienation. Faced with the social reality of controlled consumption by the symbol, Lefebvre seeks to change through cultural revolution, but he arbitrarily abandoned the classical Marxist criticism of capitalist social and economic politics, and finally the transformation of everyday life can only be reduced to a fantasy.
\end{abstract}

Keywords-Lefebvre; Consumption Alienation; Everyday Life; Symbolic Consumption

\section{INTRODUCTION}

Henri Lefebvre (1901 - 1991), "father of the critical theory of everyday life ", was also the first philosopher to introduce Marxism to France. In the grasp of the capitalist society after World War II, Lefebvre believes that industrial society, technological society, leisure society and even the consumer society cannot accurately define the basic characteristics of modern society, but only the definition of "the bureaucratic society of controlled consumption"[1] is the most scientific and accurate one. "The bureaucratic society of controlled consumption" refers to the capitalist bureaucratic society which is enslaved and controlled by the bourgeoisie through the everyday life platform to control people's daily living consumption and to use the symbol as a means. In "the bureaucratic society of controlled consumption", people cannot make their own consumption behavior, because the bourgeoisie in the capitalist society will use the mass media to regulate the consumption of people.

\section{THE REALISTIC FIELD OF CONSUMPTION ALIENATION:}

\section{EVERYDAY LIFE AND ITS “SUB-SYSTEM”}

In "the bureaucratic society of controlled consumption", the everyday life is simplified as the symbolic consumption world without characteristic; the symbolic consumption becomes the leading part of everyday life. Everyday life and its "sub-system" become the platform of the bourgeoisie to control the masses through symbolic consumption. The criticism of "the bureaucratic society of controlled consumption" is the criticism of everyday life, and the everyday life criticism is to criticize the alienation phenomenon in everyday life, especially the consumption alienation. [2] "The bureaucratic society of controlled consumption" dominates the society through the symbolic consumption in everyday life.

"The bureaucratic society of controlled consumption" consolidates its rule by firmly controlling the consumption in everyday life, and turns the everyday life dominated by consumption into a key platform for rule. The consumption in the everyday life needs specific consumption path, which 
means that there is not a complete everyday life system in the consumption, and there is only a series of parallel service, known as the "sub-systems" [1] for people to realize their different kinds of consumption needs. The consumption alienation in everyday life is not dominated and controlled by the unified system, but through the specialization of varies of "sub-systems". People can choose to consume in different systems. "Sub-systems" reveals the mechanism and specific channels of consumption alienation in everyday life. Through "sub-systems", we can focus on the specific scenes of consumption alienation. The existence of "sub-systems" shows that the consumption in everyday life is not monolithic, but presents a fragmented consumption state.

"Sub-systems" have a lot of kinds, such as television, advertising, cars, networks, fashion, leisure, tourism and so on. When we consume by the "sub-system", we can see that the symbolic consumption lies within. The unique symbol consumption system in every "sub-systems" is the embodiment of the whole social symbol consumption system. The "sub-system" is like the "isotope" [1] in the social space, attracts or repel. "Sub-systems" are the symbolic function system of consumption. Each specific "sub-systems" has independent symbol coding and consumption strategy. For example, automobile industry is a symbolic consumption "sub-system". The car is not only a kind of technical advantages; it also has the social and economic significance. We can interpret the owner through his car's performance, cost and other comprehensive representation of his social class. Automobile is the status symbol of social class; it is consumed as a symbol of power, happiness, comfort and speed. And the consumption of different brand cars often becomes the symbol of different social status and identity. That is to say, the "sub-system" of the car has formed its own system of complete symbolic communication system.

\section{THE CONSEQUENCE OF SYMBOLIC CONSUMPTION:} NEW SOCIAL CLASS DIVISION STANDARD

Before Lefebvre, consumption alienation is regarded as the consumption of the physical goods. But Lefebvre initiates the critique of the symbol perspective of consumption alienation. He believes that consumption alienation is manifested in consumption not in order to obtain specific physical goods, but in order to consume the symbolic cultural significance of goods. Symbolic consumption means the phenomenon that people are committed to consumption in order to obtain the social and cultural symbolic meaning of specific consumer goods. In the symbol consumption system, the functional differences between commodities are no longer important, and the symbolic meaning represented by commodities becomes the primary factor of the differences between commodities. People consume commodity is not only to obtain its use value, but for the value of the social difference represented by its symbol. Symbol carries the social and cultural information, so the symbolic consumption will spread symbol meanings among people, so as to radiate to the whole society.

By judging the commodities that a person can afford, we can easily classify him or her into certain social class. Through consumption, people establish their identity and find their own class ownership. When consumption becomes the standard of dividing class, the standard of entering a certain class is relatively lower, because as long as the goods that one can consume belongs to certain class, oneself can produce the illusory sense of actually belonging to that class stratum. Compared with other class stratum qualification by birth, work and other standards, it is much easier to enter the corresponding class through consumption. Therefore, in order to try to integrate into the higher class, people can let themselves consume more like that class. That is by pursuing more and more luxurious consumption to meet their vanity and imagination. The era of embody identity through consumption has come.

Symbolic consumption has the function of reflecting social class. Through symbolic consumption, the abstract social class can be visualization through the symbol, and intuitively show the social status and identity of certain human. "Every object and product has a double existence, perceptible and false existence; All that can be consumed ( goods ) is a symbol of consumption, and consumers rely on this symbol, on the symbol of dexterity and wealth, living on 
the symbol of happiness and love; Symbols and meanings replace reality, and this substitution and transfer is but a kind of vertigo - distorting illusion, which is beyond its meaning."[1] The symbolic value implied by the consumer divides people into different identities, status and grades. By observing the symbolic value of the goods purchased by the individual, we can easily locate the person to a certain class and understand his status. The function of symbolic consumption creates a false world, which makes people understand and communicate with each other through symbols. The real reason and emotional communication between people are covered by symbols, and some are only false association based on symbolic consumption.

\section{WAY TO OVERCOME THE ALIENATION OF SYMBOLIC}

\section{CONSUMPTION: CULTURAL REVOLUTION}

Marx's labor theory of value tells us that there are human labors behind the value of the commodity, and the commodity value derived from human labor. Therefore, the consumption of goods in essence is the consumption of human labor, and to obtain the use value of goods created through human's specific labor. Lefebvre's view of consumer goods deviates from Marx's labor theory of value, and moves towards complete cultural symbolic determinism. He believes that the value of goods is not determined by human labor, but by the symbolic value behind it. The cultural symbol representing the social status is the source of the symbolic value, people purchase the goods is not to obtain the use value of the commodity, but to obtain the symbolic value of the commodity. The commodity has become the existence of complete cultural significance, away from the material attributes of labor. Consumption has become a symbol of social status in the definition of Lefebvre, and behind the symbol is the symbolic value representing the cultural level of social status. Lefebvre's definition of consumption goes to the opposite of Marx, completely ignores the material labor base of consumption, and goes to cultural determinism.

Lefebvre believes that only through the means of cultural revolution can the problems of symbolic consumption alienation to be solved. The ultimate goal of the cultural revolution is to "make everyday life a work of art" [1], and let the means of technology become a tool for the transformation of everyday life. The ultimate purpose of art revival is not only for art, but to reshape the experience of culture, and to transform the everyday life of culture. "The direct fear of natural rule and violent rule has disappeared in the former industrial society, but people today live in an era of institutionalized abstraction that you cannot escape, in an era of functional abstraction, an era of function, and a universal era of terror. Because of this, Lefebvre has always insisted that today's social liberation must be overall liberation rather than certain areas (such as economic or political or culture) libration. The libration must be the overall everyday life's liberation. [3] Through the transformation of everyday life, change the consumption alienation's control of everyday life, and finally achieve the goal of "the overall person". "The overall person" is a kind of person who completely discards all kinds of alienation, eliminates the opposite negative state between man and himself, man and others, and man and nature, and become the complete person of comprehensive development. "The overall person" as the perfect highest ideal goal, is the further interpret to Marx's "the comprehensive person". "The overall person is not only the subject of generation but also the object of production". [4] The overall person is the kind of person that overcomes all kinds of alienation.

Lefebvre believes that in the economic, political and cultural revolution, the cultural revolution is of great significance. Cultural revolution is to break the consumption of controlled bureaucratic social system, create a culture of life style, and make everyday life into art. In the face of the general alienation of consumption in everyday life, we must not only pay attention to the macro revolution in political and economy field, but also pay attention to the micro revolution in the field of everyday life. The combination of the macro - revolution and the micro - revolution can truly realize the thoroughness of the revolution. In order to change the contemporary capitalist society, we must take the change of everyday life as the center, which necessarily requires the masses to awaken from the everyday life of consumption alienation, to restore their own revolutionary and creative, 
and to run away from the everyday life covered by consumption. It is worth noting that in this case Lefebvre exaggerates the role of the micro - revolution in everyday life, by confusing people's vision and ignoring the grasp and change of the fundamental contradictions of the capitalist society. Lefebvre reduced the existence of everyday life mainly to the urban society of consumption society and bureaucracy, which undoubtedly narrowed the scope of everyday life. The cultural revolution that he proposed to overcome the alienation of everyday life fell into the mire of cultural determinism.

\section{REFERENCES}

[1] Henri Lefebvre: Everyday Life in the Modern World, London: The Penguin Press, 1971, p.60, 86,100,108,204.

[2] Henri Lefebvre: Critique of Everyday Life, Volume 2, Translated by John Moore, Verso, London and New York, 2002, p.207.

[3] Liu Huaiyu: The mediocrity and magic of modernity- A Textual Interpretation of Lefebvre's Critical Philosophy in Everyday Life, Central Compilation and Translation Press, 2006, pp.43-44.

[4] Henri Lefebvre: Dialectical Materialism, Translated by John Sturrock, University of Minnesota Press, Minneapolis London, 2009, p.149. 